\title{
El proyecto de didáctica del patrimonio HA del castillo! prioriza lugares en riesgo de exclusión social
}

HA del Castillo! (Historia y Acción social en torno a las fortalezas españolas) es un proyecto, enfocado sobre todo a los niños, para dar a conocer de manera lúdica los barrios históricos situados en las faldas de los castillos que coronan algunas ciudades españolas. Desde su origen, a finales del 2018, se ha planteado acciones pedagógicas-culturales en torno al monumento en lugares en riesgo de exclusión social. Es una actividad que forma parte de las Jornadas Europeas del Patrimonio del Consejo de Europa. Se eligieron doce ubicaciones en toda la geografía española. Dos de los municipios seleccionados fueron andaluces: íllora (Granada) y La Iruela (Jaén). Aunque la primera fase finalizó en diciembre del 2019, en la actualidad se trabaja sobre los resultados obtenidos con intención de dar continuidad al proyecto.

Ángela López Sabater, Xavier Laumain, Vanesa García López de Andújar | ARAE Patrimonio y Restauración

Url de la contribución <www.iaph.es/revistaph/index.php/revistaph/article/view/4620>

Las Jornadas Europeas del Patrimonio, organizadas por el Consejo de Europa desde 1985, son el acontecimiento cultural participativo de mayor amplitud en Europa. Se trata de una iniciativa pensada para potenciar el interés por el patrimonio cultural europeo e inculcar a la ciudadanía y a las administraciones la necesidad de proteger el patrimonio cultural.

España participa activamente compartiendo una serie de actividades sobre el rico patrimonio cultural de nuestras tierras, y desde nuestro equipo de didáctica del patrimonio hemos estado trabajando los objetivos que se imponen (sensibilizar a la ciudadanía sobre la riqueza cultural, fomentar el diálogo intercultural, concienciar a la sociedad y a los responsables políticos sobre la necesidad de proteger el patrimonio...) y consecuentemente hemos podido incluir nuestras actividades en estas jornadas, destacando el proyecto HA del Castillo!

HA del Castillo! (Historia y Acción social en torno a las fortalezas españolas) es un proyecto que trabaja en las poblaciones españolas con orografía montañosa y donde su fortaleza histórica se erige coronando la población. Desde el origen del proyecto a finales del 2018, se ha planteado como una serie de acciones pedagógicas-culturales en torno al monumento en lugares en riesgo de exclusión social. A través de las representaciones en cartón reciclado de las fortalezas se pretende, por una parte, acercar estos barrios al resto de la población, investigando bajo un prisma de participación arquitectónica, sociológica y urbana, mejorando la percepción de estos espacios urbanos; y por otra, establecer mecanismos que permitan a los ciudadanos acercarse al patrimonio que los rodea (entendiendo los barrios limítrofes a las fortalezas como lugares que encierran parte de la historia ligada a la población) y hacerlos más conscientes de que estos representan una parte muy importante de su historia.

Este proyecto, además de descubrir el patrimonio y el valor del mismo entre los más pequeños, también se propone como acción puntual dentro de las líneas de participación y regeneración de espacios degradados, recuperando la atracción sobre estos conjuntos históricos que en ocasiones presentan problemáticas urbanísticas, sociales, medioambientales, etc. derivadas del abandono del centro histórico por parte de la sociedad para instalarse en zonas urbanísticas de nueva construcción.

Como parte del trabajo de investigación, se pretendió abarcar una extensión geográfica lo más fiel a la realidad de trazas de arquitectura defensiva, por tanto entre los municipios finalmente seleccionados en el proyecto, se trabajó en dos provincias andaluzas. La experiencia tuvo lugar en septiembre de 2019 en las localidades de íllora (Granada) y La Iruela (Jaén). 
Primera parada... íllora, Granada

El caso de íllora y su fortaleza es excepcional, habiendo sido restaurada hace apenas un año, acogió una jornada donde grandes y pequeños pudieron recorrer las estancias y torres más identificativas de la fortaleza en cartón, así como la recreación de sus tres aljibes que destacan en el centro de su patio de armas.

Los más de 50 participantes y sus respectivos familiares tuvieron la oportunidad de visitar, de la mano de su concejala de turismo, juventud y educación, el castillo de su pueblo, que todavía no contaba con horario de apertura al público. Un éxito de jornada en la que de nuevo se puso de manifiesto que un bien patrimonial, trabajado de modo adecuado, es una gran herramienta de aprendizaje, conocimiento, juego e inclusión.

\section{Segunda parada... La Iruela, Jaén}

Las intrincadas y empinadas calles del centro histórico de La Iruela nos llevaron a proponer la ejecución de la réplica de su castillo en el anfiteatro que se encuentra en las inmediaciones del mismo. Esto nos permitió realizar una actividad en la que no solo se producía esa deseada mezcla de participantes procedentes de distintas partes de la población, sino que éstos se encontraron también con los turistas que visitaban su castillo, y así se consiguió una composición turismo/barrio que no suele interconectar, en un momento y espacio de juego y actividades en común.

Se aprovechó el anfiteatro romano que sirve de antesala al resto de edificaciones que engloban el recinto fortificado para realizar actividades de heráldica y complementos en la vida medieval con cartón reciclado (uno de los objetivos del proyecto, 3R: reducir-reutilizar-reciclar). Mientras, con la ayuda de padres y adolescentes, concluíamos la reconstrucción del castillo en cartón, que alcanzaba dimensiones extraordinarias con sus $13 \mathrm{~m}$ de longitud. En esta ocasión la complejidad de la réplica (castillo estructurado en tres niveles, la torre del homenaje coronando, seguido de una plaza de armas y un último cordón de muralla que serpentea una escarpada peña) fue un reto que con la ayuda de nuestro equipo de historiadores y arquitectos pudimos recrear a la perfección.

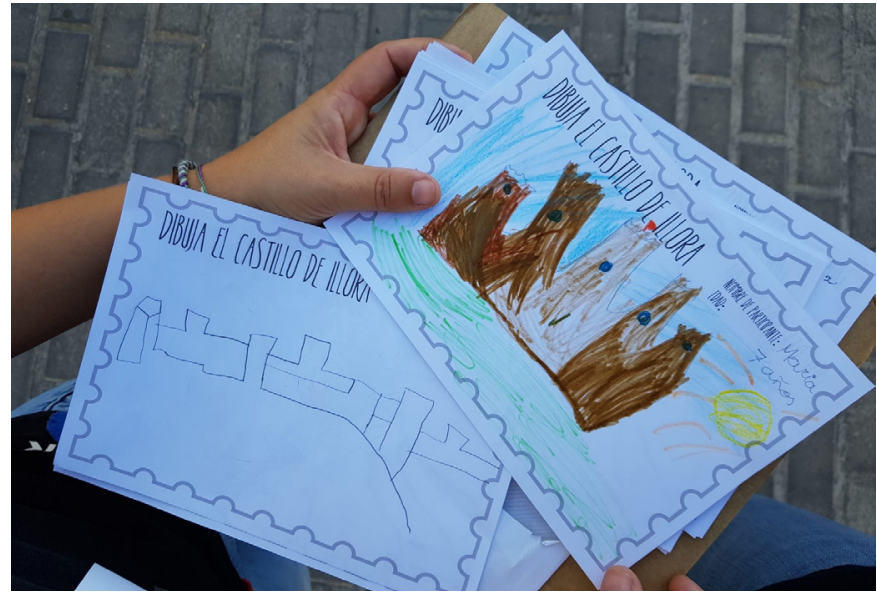

Dibujo de los participantes en íllora (Granada)

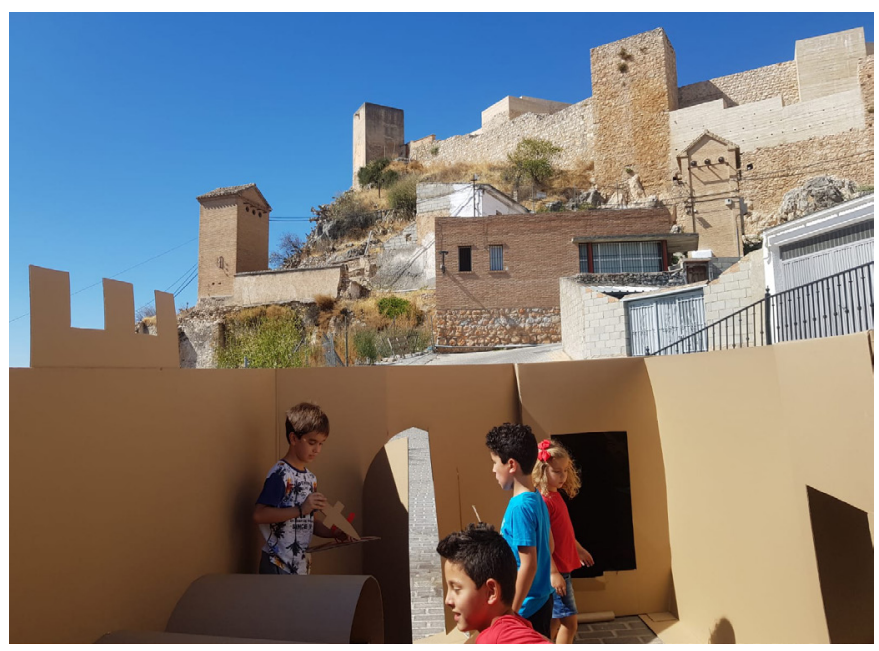

Desarrollo de la actividad en íllora (Granada)

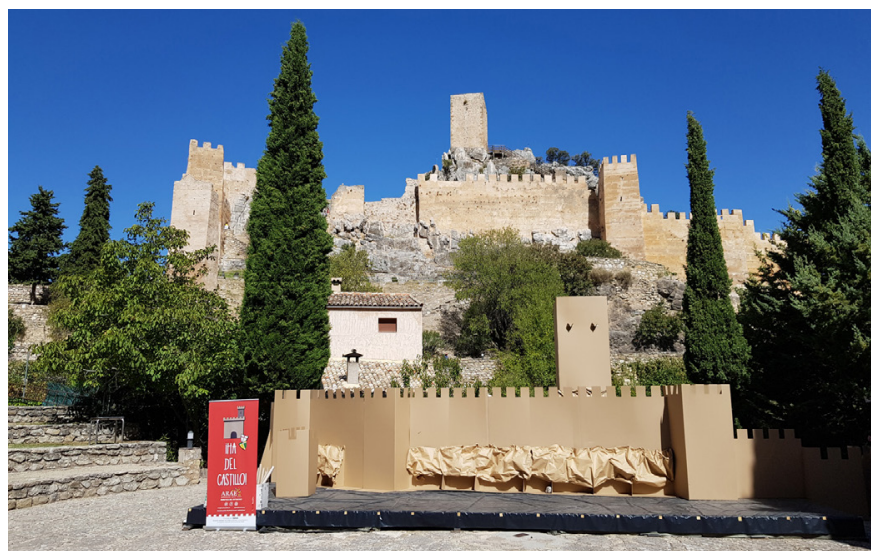

Resultado final de la reproducción de 13 m de longitud del castillo de La Iruela (Jaén), situada en el anfiteatro romano del conjunto histórico del municipio 


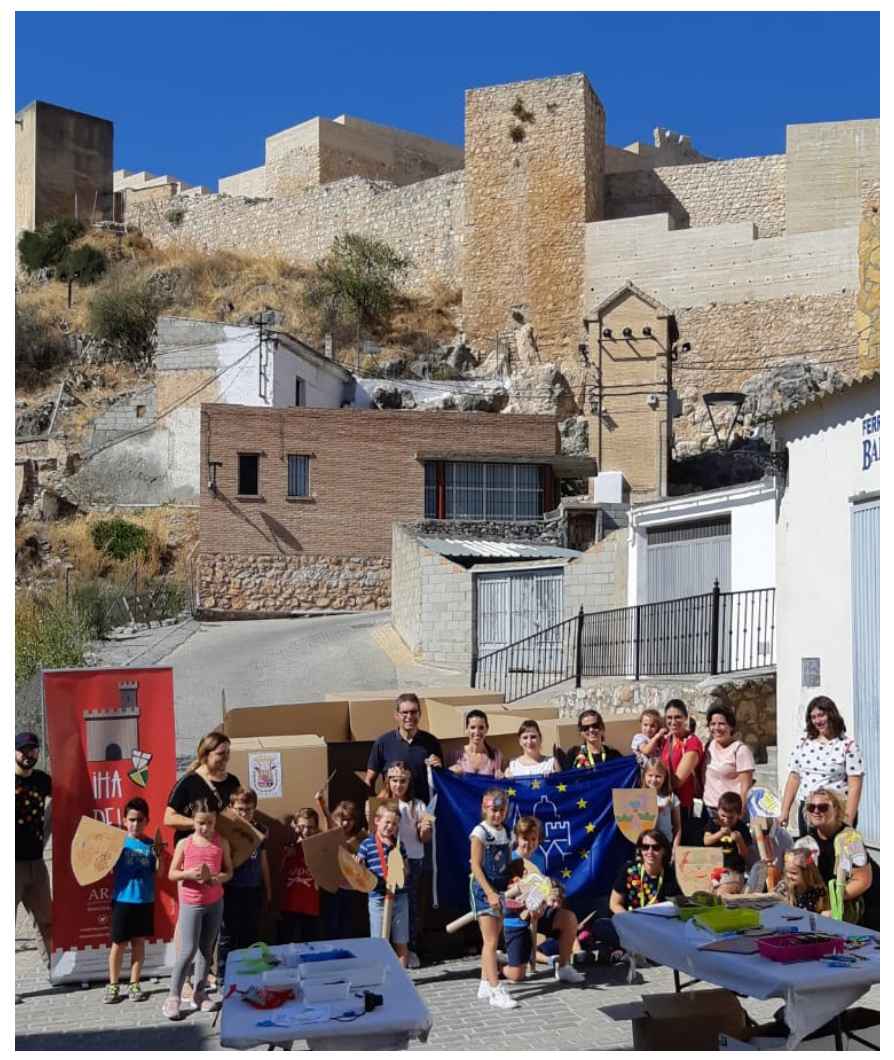

Grupo de participantes con la bandera que acredita que la actividad forma parte de las Jornadas Europeas del Patrimonio del Consejo de Europa | fotos Arae Patrimonio y Restauración, fuente de todas las imágenes

\section{Balance y reflexiones}

El proyecto de didáctica patrimonial ha sido realizado con la Beca Leonardo a Investigadores y Creadores Culturales 2018 de la Fundación BBVA ${ }^{1}$ y, aunque la primera fase finalizó en diciembre del 2019, ha tenido continuidad en los meses posteriores. En la actualidad estamos trabajando sobre los resultados obtenidos. Los datos de los más de 200 ayuntamientos entrevistados con alrededor de 50 poblaciones interesadas en la actividad didáctica de reproducción de su hito patrimonial en los barrios desfavorecidos están siendo interpretados. Las 12 intervenciones en las poblaciones seleccionadas en esta primera fase sirven de antesala a un trabajo más en profundidad sobre la relación de nuestros patrimonios y la comunidad que los hereda. Por ello, el proyecto sigue abierto e invitamos a curiosos, técnicos de patrimonio, gestores culturales y administraciones a contactar con nuestro equipo para próximas visitas en Andalucía.

\section{NOTAS}

1. La Fundación no se responsabiliza de las opiniones, comentarios y contenidos incluidos en el proyecto y/o los resultados obtenidos del mismo, los cuales son total y absoluta responsabilidad de sus autores.

\section{BIBLIOGRAFÍA}

- JORNADAS Europeas de Patrimonio [en línea] <http://www. europeanheritagedays.com/Home.aspx> [Consulta: 16/04/20 20]

- LAUMAin, X.; LÓPEZ SABATER, A.; GARCía lÓPEZ de ANDÚJAR, V. (2014) Patrimonio para niños: una propuesta didáctica para la sensibilización hacia el Patrimonio Cultural. En FONTAL MERILLAS, O.; IBÁÑEZ ETXEBERRIA, A.; MARTÍN SÁNCHEZ, L. (coord.) Reflexionar desde las experiencias Una visión complementaria entre España, Francia y Brasil. Actas del II congreso internacional de educación patrimonial. Madrid: IPCE/OEPE, 2014, pp. 147-158

- LAUMAiN, X.; LÓPEZ SABATER, A. (2016) El bien patrimonial como herramienta para la inclusión social. El caso de las fortalezas en las poblaciones españolas. En OLCINA DOMÉNECH, M. H.; ESPINOSA RUIZ, A.; SOLER DÍAZ, J. A.; GARCÍA SANDOVAL, J.; DOMÍNGUEZ ARRANZ, M. A. (coord.) Accesibilidad e inclusión en el turismo de patrimonio cultural y natural: [actas del] 3er Congreso Internacional Educación y accesibilidad en museos y patrimonio [celebrado en el MARQ y Vilamuseu los días 13, 14 y 15 de octubre de 2016]. Alicante: Diputación Provincial de Alicante Museo Arqueológico de Alicante-MARQ, 2018, pp. 203-206

- PLAN Nacional de Educación y Patrimonio [en línea] Ministerio de Educación, Cultura y Deporte <http://www. culturaydeporte.gob.es/planes-nacionales/planes-nacionales/ educacion-y-patrimonio.html> [Consulta: 16/04/2020]

\section{Más información:}

http://www.hadelcastillo.es 